\title{
Waterpipe smoking cessation: knowledge, barriers, and practices of primary care physicians- a questionnaire-based cross- sectional study
}

\author{
Maya Romani, Sarah Jawhar, Manar Shalak and Jumana Antoun * (B)
}

\begin{abstract}
Background: While cigarette smoking has been considered the most relevant tobacco product worldwide, waterpipe tobacco smoking (WTS) has increased in prevalence globally and calls for more considerable attention now. However, little is known about WTS cessation knowledge and clinical practices among physicians, particularly in Lebanon. This study aims to examine the knowledge, barriers, and cessation practices of primary care practitioners towards WTS.

Methods: A cross-sectional study where an anonymous self-reported questionnaire was completed by physicians attending the Annual Conference of the Lebanese Society of Family Medicine for family medicine physicians, general practitioners, and internists in Lebanon.

Results: Out of 180 attendees, 105 primary care practitioners (PCPs) responded to the questionnaire. Only $38.1 \%$ of the physicians think similar techniques are used for the cessation of smoking of both cigarette and waterpipe. Similarly, $30.5 \%$ of the physicians believe that nicotine replacement therapy works in the cessation of waterpipe smoking. There was a statistically significant difference between the percentage of physicians who counsel for cigarette smoking and those who counsel for waterpipe smoking cessation $(p=0.005)$ where $30 \%$ of the physicians tend to counsel against cigarette smoking more than waterpipe smoking.

Conclusions: This study shows a difference in the attitude and behavior of PCPs towards cigarette and waterpipe smoking cessation. Moreover, there is a lack of knowledge about water pipe smoking cessation techniques. There is a great room for continued medical education to PCPs in their private practice to improve their knowledge.
\end{abstract}

Keywords: Waterpipe smoking, Smoking cessation, Family physicians

\section{Background}

Since the turn of the twenty-first century, the tobacco product landscape has witnessed the emergence of a new wave of tobacco products, including waterpipe tobacco smoking (WTS), which has triggered alarming epidemiological trends $[1,2]$. While this practice (also known as arghile, hookah, and shisha) was limited to Southeast Asia and Eastern Mediterranean communities, it has recently begun to rise in popularity in other regions of the world $[3,4]$. Both waterpipe tobacco users

\footnotetext{
* Correspondence: ja46@aub.edu.lb

Department of Family Medicine, American University of Beirut, Riad El Solh, Beirut 11-0236, Lebanon
}

(c) The Author(s). 2020 Open Access This article is distributed under the terms of the Creative Commons Attribution 4.0 International License (http://creativecommons.org/licenses/by/4.0/), which permits unrestricted use, distribution, and reproduction in any medium, provided you give appropriate credit to the original author(s) and the source, provide a link to the Creative Commons license, and indicate if changes were made. The Creative Commons Public Domain Dedication waiver (http://creativecommons.org/publicdomain/zero/1.0/) applies to the data made available in this article, unless otherwise stated.

and non-users perceive WTS to be less harmful than cigarette smoking $[5,6]$. However, there exists compelling evidence about the harms of waterpipe smoking and detrimental effect on long-term health outcomes $[7,8]$. More specifically, several systematic reviews and metaanalyses have demonstrated the association between WTS and increased risk of lung cancer, cardiovascular diseases, abnormal pulmonary function, low birth weight, and periodontal diseases [4, 9-11]. Despite the evidence, the incorrect public perception of reduced harm is possibly driven by the introduction of flavored waterpipe tobacco (also known as Maassel), the advancement of global communication particularly the internet, 
and the lack of enforcement of waterpipe tobacco control policies $[6,12]$.

Given the growing rate of the waterpipe epidemic specifically among young adults, a recent meta-analysis has reported the Eastern Mediterranean Region to have the highest estimates for ever use of waterpipe tobacco among youth ranging from $12.9 \%$ among secondary school in Iran to $65.9 \%$ among secondary school and university students in Lebanon $[5,13]$. Meanwhile, data from other regions of the world demonstrate a similar trend. For example, recent findings from the National Adult Tobacco Survey conducted in the USA involving 118, 581 participants showed that young adults (18-24years) had the highest prevalence rate of WTS $(28.6 \%)$ compared to older adults [14]. Similarly, in Canada, the national Youth Smoking Survey that was administered in 2012/2013 revealed that $14.3 \%$ of Canadian students in grades $9-12(N=27,404)$ have reported to ever using waterpipe [15].

Therefore, smoking cessation and its associated health benefits are crucial in treating tobacco dependence through a medical intervention that includes pharmacological and behavioral approaches [16]. In addition, physicians play a significant role in promoting smoking cessation among patients [17]. More specifically, primary care physicians (PCPs) have a significant opportunity in reducing smoking rates through effective counseling since they serve as the first point of medical contact for patients, including smokers [17-19]. However, the literature shows that several factors and barriers influence physicians' provision of smoking cessation advice. Some of the identified barriers include lack of awareness, insufficient time, lack of selfefficacy, and lack of training [20,21].

Consequently, there is an urgent need for WTS to be better understood among healthcare professionals, especially among PCPs, to improve the delivery of tobacco cessation interventions [22]. Effective smoking cessation strategies and barriers to the provision of assistance among physicians had been comprehensively studied previously. Still, rare studies have examined the knowledge and evidence-based cessation clinical practices among physicians in relation to waterpipe tobacco use [23, 24].

Therefore, the purpose of this study was to explore the knowledge, attitude, practices, and barriers associated with waterpipe smoking among Lebanese PCPs. We aimed to (i) assess knowledge and attitudes regarding waterpipe smoking among physicians; (ii) assess clinic-based practices related to cigarette vs. waterpipe smoking cessation among these physicians, and (iii) assess providers' perceived barriers to providing WTS cessation intervention.

\section{Methods}

\section{Study design}

This was a cross-sectional study assessing the knowledge, attitude, and barriers towards waterpipe smoking cessation clinical-based practices among Lebanese family medicine physicians. Data was collected from selfreported questionnaires completed by physicians who attended the Annual Conference of the Lebanese Society of Family Medicine. The conference is a well-respected conference and is highly attended by family medicine physicians (approximately one-third of the total registered family physicians in the country). In Lebanon, there are around 250 registered family physicians; however, many of them practice abroad. The study received approval from the American University of Beirut Medical Center's (AUBMC) Institutional Review Board.

\section{Study population}

The study population included a convenience sample of the conference attendees (180PCPs). The attendees comprised of family medicine doctors, general practitioners, and internists residing and practicing family medicine in Lebanon.

\section{Instrument development}

A questionnaire was developed in English by family medicine physicians at AUBMC and consisted of 21 questions covering the following topics (See Additional file 1):

1. Physicians' demographic information and tobacco use status

2. Physicians' knowledge and attitudes' towards WTS

a. Familiarity with the waterpipe apparatus and its toxic content

b. Familiarity with the health outcomes of WTS (dependence, addiction, and diseases)

3. Physicians' smoking cessation clinical practice

a. Practicing the USPHS Clinical Practice Guidelines (Using the 5 A's)

b. Frequency of counseling patients on cigarette smoking and WTS

4. Physicians' barriers to the provision of WTS cessation assistance

a. Level of importance of perceived barriers to counseling patients on waterpipe smoking cessation

\section{Data collection}

Upon arrival at the conference and after completing registration, in-person oral consent was obtained from 
the attendees who were informed that the questionnaire was anonymous and voluntary. The questionnaires were distributed to the participants while the conference was taking place. After filling out the questionnaires, attendees dropped the forms in a concealed box localized next to the registration area.

\section{Data analysis}

Data were analyzed using SPSS statistical software IBM 19. Frequencies and percentages were used to measure the knowledge, practice, and barriers towards waterpipe smoking cessation. Chi-square and Fisher exact tests were used to compare the attitudes, knowledge, and barriers among the various demographics' characteristics of PCPs. Statistical significance was defined as $p$-value $\leq 0.005$.

\section{Results}

\section{Physicians' characteristics}

Of the 180 PCPs who attended the conference, 105 physicians completed the questionnaire (response rate $=$ $58 \%$ ). The demographics and relevant characteristics of the respondents are shown in Table 1 . Only $14.4 \%$ of participants were smokers, two thirds were family medicine physicians (63.1\%), and almost all the physicians worked in Lebanon (98\%). Less than half of the physicians had work experience of more than 15 years (43\%) whereas half (54\%) had a smoking cessation program at their practice. However, nearly two thirds $(65.2 \%)$ had not received training in smoking cessation.

\section{Knowledge and attitude of PCPs}

The results of the questions asked to assess the participants' knowledge regarding waterpipe smoking are summarized in Table 2. Most respondents answered correctly on three to four waterpipe statements (79\%) while few answered one correctly (7\%) or all incorrect (2\%). Physicians were knowledgeable about the harmful and addictive ingredients in waterpipe smoking as well as the associated health risks, but almost half of the physicians were not aware of the cigarette equivalence of waterpipe smoking.

\section{Smoking cessation practices among PCPs}

Nearly all physicians surveyed inquire about their patients' smoking status (Table 3). Family medicine physicians ask their patients about the type of tobacco product smoked more often than internal medicine physicians and general practitioners $(90.8 \%$ vs. $88.9 \%$ vs. $64.3 \%, p=0.005)$. Similarly, physicians who worked at academic institutions were more likely to ask the patient about type of smoking than those who worked at nonacademic workplaces $(92.3 \%$ vs. $75.5 \%, p=0.043)$.

On examining intervention methods, $38.1 \%$ of physicians thought similar techniques are used for both cigarette and
Table 1 Demographic and relevant characteristics of the PCPs

\begin{tabular}{|c|c|c|}
\hline \multirow[t]{2}{*}{ Characteristic } & \multicolumn{2}{|c|}{ Total $(N=105)$} \\
\hline & $\mathrm{N}$ & $\%$ \\
\hline \multicolumn{3}{|l|}{ Gender $(N=105)$} \\
\hline Males & 60 & 57.1 \\
\hline Females & 45 & 42.9 \\
\hline \multicolumn{3}{|l|}{ Specialty $(N=103)^{a}$} \\
\hline Family Medicine & 65 & 63.1 \\
\hline Internal Medicine & 9 & 8.8 \\
\hline General Practitioners & 28 & 27.1 \\
\hline Emergency medicine & 1 & 1.0 \\
\hline \multicolumn{3}{|l|}{ Work experience (years) $(\mathrm{N}=105)$} \\
\hline Less than 5 years & 17 & 16.2 \\
\hline $5-10$ years & 12 & 11.4 \\
\hline $11-15$ years & 17 & 16.2 \\
\hline More than 15 years & 45 & 42.9 \\
\hline Resident & 14 & 13.3 \\
\hline \multicolumn{3}{|l|}{ Place of work ${ }^{b}$} \\
\hline Academic Institution & 52 & 49.5 \\
\hline Private Practice & 62 & 59.0 \\
\hline Managed Care Organization & 27 & 25.7 \\
\hline \multicolumn{3}{|l|}{ Country of work ${ }^{\mathrm{a}}(\mathrm{N}=104)$} \\
\hline Lebanon & 102 & 98.1 \\
\hline Bahrain & 1 & 1.0 \\
\hline UAE & 1 & 1.0 \\
\hline \multicolumn{3}{|c|}{$\begin{array}{l}\text { Received/participated in training program } \\
\text { for smoking cessation }{ }^{\mathrm{a}}(\mathrm{N}=95)\end{array}$} \\
\hline Yes & 33 & 34.7 \\
\hline No & 62 & 65.2 \\
\hline $\begin{array}{l}\text { Presence of smoking cessation } \\
\text { programcessationprogram } \\
\text { at the work of place* }\end{array}$ & 57 & 54.3 \\
\hline \multicolumn{3}{|l|}{ Smoking status ${ }^{\mathrm{a}}(\mathrm{N}=104)$} \\
\hline Smoker & 15 & 14.4 \\
\hline Cigarettes & 9 & 60 \\
\hline Waterpipe & 5 & 33.3 \\
\hline Cigar & 1 & 6.7 \\
\hline Non-smoker & 86 & 82.7 \\
\hline Ex-smoker & 3 & 2.9 \\
\hline Cigarettes & 3 & 100 \\
\hline
\end{tabular}

${ }^{a}$ Missing values exist

${ }^{\mathrm{b}}$ More than one answer was allowed

waterpipe smoking cessation. However, only $31.7 \%$ of respondents believe that nicotine replacement therapy (NRT) works in waterpipe smoking cessation. As for counseling, there was a statistically significant difference between those who counselled against cigarette smoking vs. waterpipe 
Table 2 Percent of PCPs giving correct answers on WTS statements

\begin{tabular}{|c|c|c|c|}
\hline \multirow[t]{2}{*}{ Statement } & Agree & Neutral & \multirow[t]{2}{*}{ Disagree } \\
\hline & \multicolumn{2}{|c|}{$N=101(\%)$} & \\
\hline Water pipe contains little toxicants because the smoke passes through a small receptacle of water. ${ }^{a}$ & $9(9.0)$ & $11(11.0)$ & $80(80.0)$ \\
\hline Water pipe delivers the addictive drug nicotine as is the case of cigarette. & $80(79.2)$ & $12(11.9)$ & $9(8.9)$ \\
\hline During one session the water pipe smoker may inhale as much smoke as in 100 cigarettes. & $54(53.5)$ & $17(16.8)$ & $30(29.7)$ \\
\hline Water pipe smokers are at risk for the same diseases as cigarettes smokers (cancer, heart and lung disease). & $92(91.1)$ & $5(5.0)$ & $4(4.0)$ \\
\hline
\end{tabular}

${ }^{\mathrm{a}}$ Missing values exist $(N=100)$

smoking. $12.4 \%$ of those who counsel against cigarette smoking do not counsel for WTS. This was paralleled by the result that $29.3 \%$ of the physicians answered that they tend to counsel against cigarette smoking more than waterpipe smoking and another $19.2 \%$ were neutral. Moreover, $80.2 \%$ of non-smokers physicians often counseled against cigarettes compared to $53.3 \%$ of smoker physicians $(p=$ 0.048) (excluding 3 ex-smokers). However, no significant relation was found between counseling against WTS and physicians' smoking status.

Meanwhile, there was a statistically significant difference between arranging for follow-up visits for cigarette smoking vs. waterpipe smoking; however, $29.3 \%$ of physicians who often/sometimes arrange for following for cigarettes fail to do that for those who smoke waterpipe $(p=0.000)$.

\section{Perceived barriers to providing waterpipe smoking cessation intervention}

The three perceived barriers recognized by most physicians as very important to the provision of waterpipe smoking cessation advice were patient incompliance (79.1\%), limited training and knowledge on smoking cessation $(78.7 \%)$, and lack of available cessation programs (77.5\%) (Table 4). These are followed by patients' disinterest in quitting (72.5\%) and lack of time during patient consultation (69.8\%). Meanwhile, half (50\%) of the respondents believed that the smoking status of a physician is not a significant barrier to counseling patients on waterpipe smoking cessation.

\section{Discussion \\ Summary}

Implementing effective evidence-based tobacco control strategies in Lebanon is crucial in combating the expanding tobacco epidemic. Unfortunately, clinical smoking cessation guidelines have focused on traditional cigarette consumption with a limited concentration on alternative tobacco products such as WTS, which calls for urgent acknowledgement and understanding and WTS cessation approaches among PCPs who play a vital role in facilitating smoking cessation [25].

\section{Strengths and limitations}

This is the first study to investigate the knowledge, barriers, and clinical-based practices of Lebanese PCPs' regarding WTS smoking cessation interventions. To our knowledge, there are no studies of a similar subject in Lebanon or worldwide to make comparison. This is the main strength of this study. The relatively small sample in this study might make it difficult to assess the causation of the lack of information regarding the waterpipe smoking cessation practice. As the participants were recruited at a medical conference, it may affect generalizability to primary care physicians in Lebanon. Nevertheless, the fact that the results showed a lack of knowledge about waterpipe smoking cessation techniques as compared to cigarette smoking is alarming, taking into consideration that the sample is supposed to be more up-to-date in medical knowledge as they are conference attendees.

Table 3 Smoking cessation practices of PCPs

\begin{tabular}{|c|c|c|c|}
\hline \multirow[t]{2}{*}{ Question } & Often & Sometimes & Seldom/Never \\
\hline & \multicolumn{3}{|c|}{$N=105(\%)$} \\
\hline How often do you ask if your patient smokes? & $99(94.3)$ & $3(2.9)$ & $3(2.9)$ \\
\hline How often do you ask your patients about type of smoking? & $88(83.8)$ & $14(13.3)$ & $3(2.9)$ \\
\hline How often do you counsel your patients about cigarette smoking cessation? & $79(75.2)$ & $20(19.0)$ & $6(5.7)$ \\
\hline How often do you arrange follow up visits to discuss cigarette smoking cessation? & $17(16.3)$ & $42(40.4)$ & $45(43.3)$ \\
\hline How often do you warn your patients about waterpipe health dangers? & $78(75.0)$ & $15(14.4)$ & $11(10.6)$ \\
\hline How often do you counsel patients about waterpipe smoking cessation? & $65(63.1)$ & $22(21.4)$ & $16(15.5)$ \\
\hline How often do you arrange follow up visits to discuss waterpipe smoking cessation? & $17(16.5)$ & $26(25.2)$ & $60(58.3)$ \\
\hline
\end{tabular}


Table 4 Level of importance of perceived barriers to the provision of waterpipe smoking cessation intervention among PCPS

\begin{tabular}{|c|c|c|c|}
\hline \multirow[t]{2}{*}{ Perceived barrier } & Very important/important & Neutral & Not important \\
\hline & \multicolumn{3}{|l|}{ N (\%) } \\
\hline Patients are not compliant & $72(79.1)$ & $5(5.5)$ & $14(15.4)$ \\
\hline Limited training and knowledge on smoking cessation & $60(78.7)$ & $6(6.7)$ & $13(14.6)$ \\
\hline Lack of available smoking cessation referring clinic or program & $69(77.5)$ & $11(12.4)$ & $9(10.1)$ \\
\hline Patients are not interested & $66(72.5)$ & $12(3.2)$ & $13(14.3)$ \\
\hline Lack of time during patient consultation & $60(69.8)$ & $18(20.9)$ & $8(9.3)$ \\
\hline Patients lack awareness about water pipe harms & $63(69.2)$ & $9(9.9)$ & $19(20.9)$ \\
\hline Lack of personal knowledge about water pipe smoking cessation & $61(67.8)$ & $12(13.3)$ & $17(18.9)$ \\
\hline Waterpipe smoking is considered a norm in special places by the community & $57(63.3)$ & $11(12.2)$ & $22(24.4)$ \\
\hline Lack of knowledge about the harms of waterpipe & $54(60.0)$ & $11(12.2)$ & $25(27.8)$ \\
\hline Cost of medications and clinic visit & $53(58.9)$ & $21(23.3)$ & $16(17.8)$ \\
\hline No expected benefit as patients will continue to smoke anyway & $45(52.3)$ & $20(23.3)$ & $21(24.4)$ \\
\hline The physician smokes & $29(38.2)$ & $9(11.8)$ & $38(50.0)$ \\
\hline
\end{tabular}

\section{Comparison with existing literature Demographic characteristics}

In this study, only $14.3 \%$ of the respondents were smokers, which is less than the national smoking rate (38.5\%). This rate is lower than in other studies carried out in Makkah, Saudi Arabia among primary health-care physicians (26\%) and in Alexandria, Egypt among primary health care (PHC) personnel $(45 \%)$ [26, 27]. However, this figure is higher compared to studies done in developed countries such as USA (7\%) and UK (4\%).

While 54\% reported having a smoking cessation program at their practice, only $34.7 \%$ of PCPs reported receiving or participating in a training program for smoking cessation which is higher than that found in Egypt (30\%), Jordan (26.6\%), Bahrain (11.6\%), Kuwait (12.6\%), and Armenia (26.9\%) [3]. However, this result was lower than that found in Palestine (43.2\%) and Riyadh (68\%) [28, 29]. These responses might explain why $78.7 \%$ believed that limited training and knowledge in this field is perceived as a very significant barrier to providing smoking cessation assistance to patients. One way to eliminate the barrier associated with lack of training is by training physicians in smoking cessation, during medical school or in the form of continuing education, since it has been positively associated with better practice and engagement in smoking cessation according to studies performed in Egypt and Switzerland [27, 30, 31].

\section{Knowledge and attitudes}

The present study revealed existing knowledge among most physicians (79\%) about the harms of waterpipe smoking, its associated risk of dependence, and its detrimental health outcomes. This is way higher than a study done in England where it shows that over half of general practitioners were knowledgeable on the topic [32].
However, this finding is in accordance with data from a study conducted among physicians regarding shisha smoking in Pakistan. In addition, half of our respondents were not familiar with WTS and its cigarette equivalence, similar to a study done in England [32]. One reason could be due to a lack of awareness among physicians about research regarding the lethal toxins and chemicals added to waterpipe smoke. According to the literature, waterpipe smoke contains higher levels of metals such as arsenic, lead and nickel, 36 times more tar, 15 times more carbon monoxide, and up to 10 cigarettes' worth of nicotine and 100 cigarettes' worth of smoking inhalation for a single waterpipe use episode.

\section{Smoking cessation practices}

Most surveyed physicians often inquired about their patients' smoking status and tobacco use (94.3 and 83.8\%, respectively). This rate is higher than that found in Egypt (49.5\%), Saudi Arabia (73.4\%), and the U.S (66.4\%), which suggests that almost all our PCPs follow the U.S public health service clinical practice guidelines regarding tobacco dependence $[28,30]$. This has a tremendous effect on tobacco smoking cessation since brief advice ( $\leq$ $5 \mathrm{~min}$ ) in clinical settings can lead to a quit rate of 2 to $4 \%$, and PCPs are the first to hold this responsibility.

In our study, family medicine physicians asked and counseled their patients about the type of tobacco product smoked more than internal medicine physicians and general practitioners $(90.8 \%$ vs. $88.9 \%$ vs. $64.3 \%, p=$ 0.005). Similarly, a national study in the U.S. revealed that PCPs were more likely than other specialties to offer smokers assistance to quit, however, regarding asking their patients about their smoking status, all healthcare professionals, including primary care physicians, psychiatrists, and emergency physicians) do that equally. 
Regarding the intervention methods, 38.1\% thought similar techniques are used for both cigarette and waterpipe smoking cessation. But still physicians tend to counsel against cigarette smoking more than against WTS (29.3\%). Moreover, $29.3 \%$ of physicians who arrange for follow-up for cigarette fail to do so for waterpipe. This indicates the lack of evidence on interventions and lack of knowledge.

\section{Physicians' perceived barriers to providing WTS cessation interventions}

The majority of the physicians believed that patient incompliance, limited training and knowledge on smoking cessation, lack of available cessation programs, patients' disinterest in quitting and lack of time during patient consultation are very important barriers that interfere with promoting waterpipe smoking cessation. Our findings are consistent with earlier studies conducted in Gulf countries and Europe that have examined factors influencing PCPs' engagement in smoking cessation $[9,17,20,21]$, which have revealed time constraint [21,33-35], lack of training $[21,28,33-35]$, and patients' disinterest in quitting [28] to be the most common perceived barriers among healthcare professionals. Interestingly, $50 \%$ of the physicians did not believe that their own smoking status is an important barrier that affects their smoking cessation practices which is in accordance with studies performed in Palestine, Kuwait, and Bahrain where respondents were in the lowest agreement with the statement. However, these studies investigated barriers addressing smoking cessation targeting cigarette consumption, but not waterpipe smoking cessation.

\section{Conclusions}

This study shows a difference in the attitude and behavior of PCPs towards cigarette and waterpipe smoking cessation. Moreover, there is a lack of knowledge about waterpipe smoking cessation techniques. This is due to the lack of training for physicians. Hence, eliminating this barrier by introducing smoking cessation techniques, early on in the physicians' medical education in medical school is crucial. In addition, there is a great room for continued medical education to PCPs in their private practice to improve their knowledge.

\section{Supplementary information}

Supplementary information accompanies this paper at https://doi.org/10. 1186/s12875-020-1095-4.

Additional file 1. Family physicians and waterpipe smoking cessation: survey of attitudes and barriers

\section{Abbreviations}

NRT: Nicotine replacement therapy; PCPs: Primary care practitioners; PHC: Primary health care; USPHS: United States public health service; WTS: Waterpipe tobacco smoking

\section{Acknowledgments}

Not applicable.

\section{Authors' contributions}

MS worked on the IRB proposal, first draft, data collection and entry, and final manuscript. SJ worked on the results interpretation, and final manuscript. JA and MR were involved with the design, data analysis and statistics, and final manuscript. All authors have read and approved the manuscript.

\section{Funding}

Not applicable.

\section{Availability of data and materials}

All data generated or analysed during this study are included in this published article.

\section{Ethics approval and consent to participate}

The study received ethical approval from the American University of Beirut (AUB) Institutional Review Board. There was an informed consent attached to the survey. By filling the survey, the participants gave their consent to participate in the research.

\section{Consent for publication}

Not applicable.

\section{Competing interests}

The authors declare that they have no competing interests.

Received: 26 November 2019 Accepted: 23 January 2020

Published online: 30 January 2020

\section{References}

1. Akl EA, Gunukula SK, Aleem S, Obeid R, Jaoude PA, Honeine R, Irani J. The prevalence of waterpipe tobacco smoking among the general and specific populations: a systematic review. BMC Public Health. 2011;11:244.

2. Ward KD. The waterpipe: an emerging global epidemic in need of action. Tob Control. 2015;24(Suppl 1):i1-2.

3. Maziak W, Nakkash R, Bahelah R, Husseini A, Fanous N, Eissenberg T. Tobacco in the Arab world: old and new epidemics amidst policy paralysis. Health Policy Plan. 2014;29(6):784-94.

4. Montazeri Z, Nyiraneza C, El-Katerji H, Little J. Waterpipe smoking and cancer: systematic review and meta-analysis. Tob Control. 2017;26(1):92-7.

5. Akl EA, Ward KD, Bteddini D, Khaliel R, Alexander AC, Lotfi T, Alaouie H, Afifi $R A$. The allure of the waterpipe: a narrative review of factors affecting the epidemic rise in waterpipe smoking among young persons globally. Tob Control. 2015:24(Suppl 1):i13-21.

6. Maziak W, Taleb ZB, Bahelah R, Islam F, Jaber R, Auf R, Salloum RG. The global epidemiology of waterpipe smoking. Tob Control. 2015;24(Suppl 1): i3-i12.

7. Ki-Hyun Kim EK. Shamin Ara Jahan: Waterpipe tobacco smoking and its human health impacts. J Hazard Mater. 2016;317:229-36.

8. Waziry R, Jawad M, Ballout RA, Al Akel M, Akl EA. The effects of waterpipe tobacco smoking on health outcomes: an updated systematic review and meta-analysis. Int J Epidemiol. 2017:46(1):32-43.

9. Rezk-Hanna M, Benowitz NL. Cardiovascular effects of hookah smoking: potential implications for cardiovascular risk. Nicotine Tob Res. 2019;21(9): 1151-61.

10. Raad D, Gaddam S, Schunemann HJ, Irani J, Abou Jaoude P, Honeine R, Akl EA. Effects of water-pipe smoking on lung function: a systematic review and meta-analysis. Chest. 2011;139(4):764-74.

11. Ramoa CP, Eissenberg T, Sahingur SE. Increasing popularity of waterpipe tobacco smoking and electronic cigarette use: implications for oral healthcare. J Periodontal Res. 2017;52(5):813-23.

12. Akl EA, Jawad M, Lam WY, Co CN, Obeid R, Irani J. Motives, beliefs and attitudes towards waterpipe tobacco smoking: a systematic review. Harm Reduct J. 2013;10:12

13. Jawad M, Charide R, Waziry R, Darzi A, Ballout RA, Akl EA. The prevalence and trends of waterpipe tobacco smoking: a systematic review. PLoS One. 2018;13(2):e0192191. 
14. Salloum RG, Thrasher JF, Kates FR, Maziak W. Water pipe tobacco smoking in the United States: findings from the National Adult Tobacco Survey. Prev Med. 2015;71:88-93.

15. Minaker LM, Shuh A, Burkhalter RJ, Manske SR. Hookah use prevalence, predictors, and perceptions among Canadian youth: findings from the 2012/2013 youth smoking survey. Cancer Causes Control. 2015;26(6):831-8.

16. WHO Tobacco Free Initiative. The role of health professionals in tobacco control. 2005. Retrieved from https://www.who.int/tobacco/resources/ publications/wntd/2005/bookletfinal_20april.pdf.

17. Stead LF, Bergson G, Lancaster T. Physician advice for smoking cessation. Cochrane Database Syst Rev. 2008:(2):Cd000165.

18. Sox HC. The future of primary care. Ann Intern Med. 2003;138(3):230-2.

19. Okuyemi KS, Nollen NL, Ahluwalia JS. Interventions to facilitate smoking cessation. Am Fam Physician. 2006;74(2):262-71.

20. Stead M, Angus K, Holme I, Cohen D, Tait G. Factors influencing European GPs' engagement in smoking cessation: a multi-country literature review. Br J Gen Pract. 2009:59(566):682-90.

21. Vogt F, Hall S, Marteau TM. General practitioners' and family physicians' negative beliefs and attitudes towards discussing smoking cessation with patients: a systematic review. Addiction (Abingdon, England). 2005;100(10): 1423-31.

22. Mohammed Jawad HK. Fiona Hamilton: shisha guidance for GPs: eliciting the hidden history. Br J Gen Pract. 2012;62(595):66-7.

23. Maziak W, Jawad M, Jawad S, Ward KD, Eissenberg T, Asfar T. Interventions for waterpipe smoking cessation. Cochrane Database Syst Rev. 2015;(7): Cd005549.

24. Fiore $M C$, Jaen CR. A clinical blueprint to accelerate the elimination of tobacco use. Jama. 2008;299(17):2083-5.

25. OCP VS, Williams S, Barchilon V, Baxter N, Jawad M, Katsaounou PA, Kirenga BJ, Panaitescu C, Tsiligianni IG, Zwar N, et al. Treating tobacco dependence: guidance for primary care on life-saving interventions. Position statement of the IPCRG. NPJ Prim Care Respir Med. 2017;27(1):38.

26. Ahmad HM, BAA A-T, Hegazy A a, Asiri SI. Knowledge, attitude, and practice among primary health-care physicians toward smoking cessation in Makkah, Saudi Arabia. Int J Med Sci Public Health. 2016;5(4):714-24.

27. Sabra AA. Smoking attitudes, behaviours and risk perceptions among primary health care personnel in urban family medicine centers in Alexandria. J Egypt Public Health Assoc. 2007;82(1-2):43-64.

28. Jradi H. Awareness, practices, and barriers regarding smoking cessation treatment among physicians in Saudi Arabia. J Addict Dis. 2017;36(1):53-9.

29. Zabadi HA, Musmar S, Hassouna A, Shtaiwi D. Cigarettes and Water Pipe Smoking Prevalence, Knowledge, and Attitudes Among the Palestinian Physicians in the West Bank. Tob Use Insights. 2018;11 1179173×18813369.

30. Elmoghazy Essam HMNS, Zaki Laila M, Amin Wagdy A. Effect of training and smoking status of physicians on smoking cessation practices in Egypt. Egypt J Chest Dis Tuberc. 2018;67(3):323-8.

31. Jacot Sadowski I, Ruffieux C, Cornuz J. Self-reported smoking cessation activities among Swiss primary care physicians. BMC Fam Pract. 2009;10:22.

32. Jawad M, Hamilton FL, Millett C, Albeyatti A, Ananthavarathan P. Knowledge and attitudes of waterpipe tobacco smoking among GPs in England. 2014; 64(622):222-3.

33. Shafagoj YA, Mohammed FI, Hadidi KA. Hubble-bubble (water pipe) smoking: levels of nicotine and cotinine in plasma, saliva and urine. Int $J$ Clin Pharmacol Ther. 2002;40(6):249-55.

34. Knishkowy B, Amitai Y. Water-pipe (narghile) smoking: an emerging health risk behavior. Pediatrics. 2005;116(1):e113-9.

35. Twardella D, Brenner $\mathrm{H}$. Lack of training as a central barrier to the promotion of smoking cessation: a survey among general practitioners in Germany. Eur J Pub Health. 2005;15(2):140-5.

\section{Publisher's Note}

Springer Nature remains neutral with regard to jurisdictional claims in published maps and institutional affiliations.

Ready to submit your research? Choose BMC and benefit from:

- fast, convenient online submission

- thorough peer review by experienced researchers in your field

- rapid publication on acceptance

- support for research data, including large and complex data types

- gold Open Access which fosters wider collaboration and increased citations

- maximum visibility for your research: over $100 \mathrm{M}$ website views per year

At $\mathrm{BMC}$, research is always in progress.

Learn more biomedcentral.com/submissions 